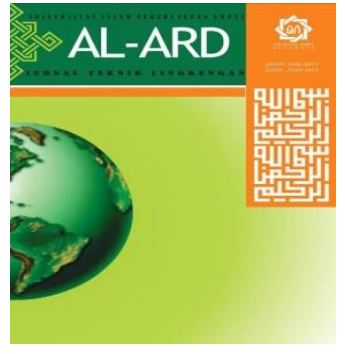

AL-ARD: JURNAL TEKNIK LINGKUNGAN

Vol.3 No.2 - Maret 2018 (39-45)

AL-ARD

JURNAL

TEKNIK LINGKUNGAN

www.al-ard.uinsby.ac.id

\title{
SISTEM PENGELOLAAN LIMBAH PADAT B3 DI RUMAH SAKIT MUHAMMADIYAH BABAT KABUPATEN LAMONGAN
}

\author{
Nahawanda Ahsanu Amala ${ }^{1}$, Shinfi Wazna Auvaria ${ }^{2}$, Sulistiya Nengse 3, Dela \\ Novita Arianie 4 \\ 1,2,3 Program Studi Teknik Lingkungan Fakultas Sains dan Teknologi Universitas Islam Negeri Sunan \\ Ampel, Surabaya, Indonesia \\ nahawanda00@gmail.com ${ }^{1}$, $\underline{\text { shinfiwazna@uinsby.com }}^{2}$, $\underline{\text { sulistiya703@gmail.com }}^{3}$ \\ ${ }^{4}$ Rumah Sakit Muhammadiyah Babat, Lamongan, Indonesia
}

\begin{abstract}
Muhammadiyah Babat Hospital in Lamongan District is one of the hospitals producing hazardous solid waste. Hazardous solid waste from the hospital has the potential environmental impacts and disrupt the public health both within the environment of the Hospital and surrounding communities, if not managed properly. Hazardous solid waste management system in the Hospital needs to be implemented properly and correctly in accordance with Government Regulation No. 101 of 2014 and KEPMENKES No.1204 / MENKES / SK / X / 2004. This research method using qualitative descriptive method by collecting primary and secondary data. Primary data obtained from observation and treatment in the field by weighing the quantity of hazardous solid waste and documentation of existing hazardous solid waste management, and interview. While secondary data obtained through study of literaturs and hospital documents related to the management of hazardous solid waste. The results showed that management system of hazardous solid waste at Muhammadiyah Babat Hospital was quite good and in accordance with Government Regulation and KEPMENKES. However, there are still some facilities that are not available to support the management of hazardous solid waste. Unavailable facilities include drainage channels, spill reservoirs, easily accessible APARs, and first aid facilities in the temporary landfill of hazardous solid waste in hospital. Suggestions that can be submitted to the conclusion of this research is the need for additional supporting facilities in temporary landfill of hazardous solid waste, in accordance with the applicable regulations, such as drainage channels, spill reservoirs, etc.
\end{abstract}

Keywords: solid waste, hazardous solid waste, management, hospital.

\section{Abstrak}

Rumah Sakit Muhammadiyah Babat di Kabupaten Lamongan merupakan salah satu rumah sakit penghasil limbah padat B3. Limbah padat B3 dari Rumah Sakit berpotensi mencemari lingkungan dan menggangu kesehatan masayarakat baik di dalam lingkungan Rumah Sakit maupun masyarakat sekitar, jika tidak dikelola dengan baik. Sistem pengelolaan limbah padat B3 di Rumah Sakit perlu dilaksanakan secara baik dan benar sesuai dengan PP Nomor 101 Tahun 2014 dan KEPMENKES No.1204/MENKES/SK/X/2004. Metode penelitian ini menggunakan metode deskriptif kualitatif dengan mengumpulkan data primer dan sekunder. Data primer didapatkan dari hasil observasi dan perlakuan di lapangan (penimbangan kuantitas limbah padat B3 dan dokumentasi pengelolaan limbah padat B3 eksisting), serta wawancara. Sedangkan data sekunder didapatkan melalui studi literatur dan dokumen rumah sakit yang berkaitan dengan pengelolaan limbah padat B3. Hasil penelitian menunjukan bahwa sistem pengelolaan limbah padat B3 di Rumah Sakit Muhammadiyah Babat sudah cukup baik dan sesuai dengan Peraturan Pemerintah dan KEPMENKES. Namun, masih terdapat beberapa fasilitas yang belum tersedia untuk menunjang pengelolaan limbah padat B3. Fasilitas yang belum tersedia diantaranya saluran buangan, bak penampung tumpahan, APAR yang mudah dijangkau, serta P3K di ruangan TPS B3. Saran yang dapat disampaikan pada kesimpulan penelitian ini adalah perlunya penambahan fasilitas penunjang di TPS B3, sesuai dengan peraturan yang berlaku seperti saluran buangan, bak penampung tumpahan, dll. Kata Kunci: limbah padat, limbah padat B3, pengelolaan, rumah sakit. 


\section{PENDAHULUAN}

Limbah padat medis menurut Permenkes No. 1204 Tahun 2004 adalah semua limbah yang dihasilkan dari kegiatan rumah sakit yang berbentuk padat sebagai akibat kegiatan rumah sakit (Menteri Kesehatan Republik Indonesia, 2004). Sedangkan menurut WHO (dalam Komilis, 2012), limbah medis merupakan limbah yang dihasilkan oleh kegiatan layanan kesehatan yang mencakup berbagai macam bahan, seperti jarum suntik bekas, pakaian kotor, bagian tubuh, sampel diagnostik, darah, bahan kimia, obat-obatan, dan perangkat medis.

Sumber utama limbah medis berasal dari rumah sakit, klinik medis, apotek, balai kesehatan, laboratorium medis dan biomedis, pusat penelitian medis, pusat otopsi dan kamar mayat, rumah sakit hewan, pusat penelitian hewan, bank darah, dan fasilitas kesehatan lainnya (Ananth et al., 2010).

Kecamatan Babat merupakan salah satu kecamatan di Kabupaten Lamongan yang pada Tahun 2014 memiliki jumlah penduduk sebesar $13.686 \quad$ (BPS, 2018). Jumlah penduduk yang cukup besar juga seiring dengan meningkatnya jumlah timbulan sampah yang dihasilkan di kecamatan ini. Limbah yang dihasilkan bukan hanya limbah domestik, tetapi juga limbah medis karena terdapat beberapa fasilitas kesehatan di kecamatan ini. Limbah yang dihasilkan dari rumah sakit berupa limbah medis sebesar 1,8 \% (Pokja, 2012).

Meski tergolong sedikit, pengelolaan limbah padat rumah sakit tidak dapat dilakukan layaknya limbah padat domestik pada umumnya. Sebanyak $\pm 10-25 \%$ limbah padat rumah sakit merupakan limbah B3 (Kalpana, 2016). Setiap orang yang menghasilkan limbah B3 wajib melakukan pengelolaan limbah B3 yang dihasilkan (UU No. 32, 2009). Pengelolaan Limbah B3 merupakan kegiatan yang meliputi pengurangan, penyimpanan, pengumpulan, pengangkutan, pemanfaatan, pengolahan dan/atau penimbunan limbah B3 (PP No.101, 2014)

Rumah Sakit Muhammadiyah Babat merupakan sarana pelayanan kesehatan yang didirikan sejak tahun 1968 dengan berbagai layanan yang terus berkembang sesuai kebutuhan masyarakat dalam bidang layanan kesehatan, berkapasitas 53 Tempat Tidur (TT). Jenis kegiatan medis dan pelayanan yang dilakukan di rumah sakit ini berupa Unit Instalasi Rawat Inap, Unit Instalasi Rawat Jalan, Unit Penunjang Medis, dan Unit Penunjang Non Medis. Rumah sakit ini tiap harinya menghasilkan limbah padat B3 yang harus diolah dengan baik. Proses pengelolaan limbah B3 Rumah Sakit Muhammadiyah Babat dilaksanakan serta disesuaikan dengan Kepmenkes No.1204 Tahun 2004 tentang Persyaratan Kesehatan Lingkungan Rumah Sakit dan Peraturan Pemerintah Nomor 101 Tahun 2014 tentang Pengelolaan Limbah Bahan Berbahaya dan Beracun (B3).

\section{METODE PENELITIAN}

Metode yang digunakan pada penelitian ini berupa deskriptif kualitatif. Pengumpulan data primer dilakukan dengan beberapa metode antara laian: observasi, wawancara, dan dokumentasi. Sedangkan untuk data sekunder didapatkan melalui studi literature dokumen rumah sakit. Alat yang digunakan dalam melakukan penelitian ini berupa neraca digital dan kuisioner.

\section{HASIL DAN PEMBAHASAN Sumber Limbah Padat B3}

Sumber limbah B3 merupakan tempat dihasilkannya limbah padat B3. Setiap ruangan/unit kerja di rumah sakit merupakan penghasil limbah. Jenis sampah dari setiap ruangan berbeda-beda sesuai dengan penggunaan dari setiap ruangan/unit yang bersangkutan (Depkes, 2004). Sumber limbah padat B3 di Rumah Sakit Muhammadiyah Babat berasal dari berbagai tempat, antara lain: kamar bersalin, Instalasi Gawat Darurat (IGD), poli mata, poli gigi, poli umum, poli jantung, poli anak, poli dalam, laboratorium, kamar obat, kamar operasi, dan kantor. Limbah padat B3 yang dihasilkan kebanyakan berupa jenis limbah padat B3 infeksius dan sebagian kecil lainya berupa limbah padat B3 beracun dan mudah meledak. Sumber limbah padat B3 di RS Muhammadiyah Babat disajikan pada Tabel 1.

Tabel 1. Sumber Limbah Padat B3

\begin{tabular}{cll}
\hline No & Sumber/area & \multicolumn{1}{c}{ Limbah B3 } \\
\hline 1 & Kamar & Masker disposable (masker \\
& Bersalin & $\begin{array}{l}\text { yang dapat dibuang), jarum } \\
\text { syringe, wadah darah, gunting } \\
\text { bedah. }\end{array}$ \\
& &
\end{tabular}




\begin{tabular}{|c|c|c|}
\hline No & Sumber/area & Limbah B3 \\
\hline 2 & $\begin{array}{l}\text { IGD (Instalasi } \\
\text { Gawat } \\
\text { Darurat) }\end{array}$ & $\begin{array}{l}\text { Selang infus, kateter, ampul } \\
\text { bekas, kantong darah bekas, } \\
\text { masker disposable (masker } \\
\text { yang dapat dibuang), jarum } \\
\text { syringe }\end{array}$ \\
\hline 3 & Poli mata & $\begin{array}{l}\text { Masker disposable (masker } \\
\text { yang dapat dibuang), jarum } \\
\text { syringe, ampul bekas }\end{array}$ \\
\hline 4 & Poli gigi & $\begin{array}{l}\text { Masker disposable (masker } \\
\text { yang dapat dibuang), jarum } \\
\text { syringe, ampul bekas, } \\
\text { potongan gigi }\end{array}$ \\
\hline 5 & Poli Umum & $\begin{array}{l}\text { Masker disposable (masker } \\
\text { yang dapat dibuang), jarum } \\
\text { syringe, ampul bekas }\end{array}$ \\
\hline 6 & Poli Jantung & $\begin{array}{l}\text { Masker disposable (masker } \\
\text { yang dapat dibuang), jarum } \\
\text { syringe, ampul bekas }\end{array}$ \\
\hline 7 & Poli Anak & $\begin{array}{l}\text { Masker disposable (masker } \\
\text { yang dapat dibuang), jarum } \\
\text { syringe, ampul bekas }\end{array}$ \\
\hline 8 & Poli Dalam & $\begin{array}{l}\text { masker disposable (masker } \\
\text { yang dapat dibuang), jarum } \\
\text { syringe, ampul bekas }\end{array}$ \\
\hline 9 & Laboratorium & 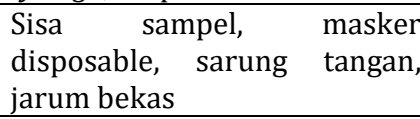 \\
\hline 10 & Kamar Obat & $\begin{array}{l}\text { Obat-obat kadaluarsa, masker } \\
\text { disposable, sarung tangan } \\
\text { bekas }\end{array}$ \\
\hline 3 & Kamar Operasi & $\begin{array}{l}\text { Dressing (pembalut/pakaian), } \\
\text { sponge (sepon/penggosok), } \\
\text { jaringan tubuh, termasuk } \\
\text { amputasi ampul bekas, } \\
\text { masker disposable, jarum } \\
\text { syringe, drapes, disposable } \\
\text { blood lancet, disposable } \\
\text { kantong emesis, pembuluh, } \\
\text { alat bedah, drainase set, } \\
\text { kantong colosiomy, } \\
\text { underpads, sarung bedah }\end{array}$ \\
\hline 7 & Kantor & $\begin{array}{l}\text { Botol tinta bekas, batrai, } \\
\text { kaleng aerosol, handscrub }\end{array}$ \\
\hline
\end{tabular}

(Sumber: Data Primer, 2017)

Dari data diatas dapat diketahui sumbersumber limbah padat B3 serta jenis limbah padat B3 dengan kategorinya. Limbah padat B3 yang dihasilkan kebanyakan berupa jenis limbah padat B3 infeksius dan sebagian kecil lainya berupa limbah padat B3 yang beracun dan mudah meledak, yang berasal dari kantor rumah sakit.

\section{Timbulan Limbah Padat B3}

Timbulan limbah padat B3 di Rumah Sakit Muhammadiyah Babat diukur menggunakan neraca digital, pengukuran dilakukan setiap hari setelah kegiatan pengumpulan. Penimbangan limbah padat B3 dilakukan untuk mengetahui limbah padat B3 yang dihasilkan sehari-hari serta untuk mempermudah pewadahan, penyimpanan serta pengangkutan limbah padat B3.

Timbulan limbah padat B3 di Rumah Sakit Muahmmadiyah Babat dibedakan menjadi infeksius dan spuit. Pada kelompok limbah padat B3 infeksius didalamnya terbagi menjadi infeksius benda tajam, infeksius dan botol infus bekas pakai. Tiap harinya Rumah Sakit Muhammadiyah Babat menghasilkan limbah padat infeksius sebesar $13,5 \mathrm{~kg}$. sedangkan untuk limbah padat B3 elektronik dihasilkan $1 \mathrm{~kg} /$ bulan. Timbulan limbah padat B3 per minggu yang dicatat mulai 25-31 Juli 2017 disajikan pada Tabel 2.

Tabel 2. Timbulan Limbah Padat B3 (Per Minggu)

\begin{tabular}{cclc}
\hline Hari & Tanggal & \multicolumn{1}{c}{ Jenis } & Jumlah \\
\hline 1 & 25 Juli 2017 & Spuit & 5,1 \\
\cline { 3 - 4 } & & Infeksius & 8,4 \\
\hline 2 & 26 Juli 2017 & Spuit & 4,8 \\
\cline { 3 - 4 } & & Infeksius & 8,2 \\
\hline 3 & 27 Juli 2017 & Infeksius & 9,45 \\
\hline 4 & 28 Juli 2017 & Spuit & 4,89 \\
\cline { 3 - 4 } & & Infeksius & 11,4 \\
\hline 5 & 29 Juli 2017 & Infeksius & 12,1 \\
\hline 6 & 30 Juli 2017 & Spuit & 4,7 \\
\cline { 3 - 4 } & & Infeksius & 9,9 \\
\hline 7 & 31 Juli 2017 & Spuit & 5,4 \\
\cline { 3 - 3 } & & Infeksius & 10,3 \\
\hline 8 & 1 Agustus 2017 & Spuit & 5,1 \\
\cline { 3 - 3 } & & Infeksius & 11 \\
\hline Rata-rata timbulan & per hari & $\mathbf{1 3 , 5} \mathbf{~ k g / h a r i}$ \\
\hline (Sumber: Data Primer, 2017) &
\end{tabular}

Limbah padat B3 yang diukur timbulanya dibedakan menjadi 2, yaitu: spuit dan infeksius. pada kelompok limbah infeksius didalamnya sudah terdapat limbah infeksius benda tajam dan botol infus bekas pakai. Tiap harinya Rumah Sakit Muhammadiyah Babat menghasilkan limbah B3 padat infeksius ratarata sebanyak 13,5 kg/hari. Sedangkan untuk limbah B3 padat elektronik dihasilkan sebanyak $\pm 1 \mathrm{~kg} /$ bulan.

\section{Pengumpulan Limbah Padat B3}

Pengumpulan limbah padat B3 merupakan salah satu tahapan pengelolaan limbah padat B3, dalam tahapan ini terdapat 4 tahapan yang harus dilakukan, yaitu: pewadahan, pelabelan, pengumpulan internal, dan penyimpanan sementara. 


\section{a. Pewadahan}

Pewadahan limbah B3 yang dilakukan di Rumah Sakit Muhammadiyah Babat menggunakan tempat sampah plastik dengan volume sesuai dengan kebutuhan rumah sakit. Pewadahan yang ada dibedakan menjadi 3 (tiga) yaitu: tempat sampah infeksius, infeksius botol infus dan infeksius benda tajam. Wadah yang digunakan untuk mewadahi limbah padat B3 kedap air, memiliki penutup dan dapat dipindahkan dengan mudah, selain itu pewadahan limbah padat B3 harus dilapisi dengan plastik tebal berwarna kuning untuk mempermudah pengumpulan limbah padat serta untuk menghindari kebocoran.

Tempat sampah infeksius dan Infeksius botol infus dilapisi plastik berwarna kuning, sedangkan untuk tempat sampah infeksius benda tajam dilapisi dengan safety box untuk mencegah terjadinya kebocoran. Setelah dilakukan pengangkutan limbah padat B3, limbah kemudian dipindah kedalam drum tebal dengan penutup yang rapat yang terletak di dalam Tempat Penyimpanan Sementara (TPS) B3.

Menurut hasil wawancara yang dilakukan dengan staf kesehatan lingkungan dikatakan bahwa jumlah wadah yang digunakan untuk limbah infeksius sebanyak 23 buah yang tersebar diseluruh ruang di RS Muhammadiyah Babat. Untuk wadah limbah benda tajam atau safety box terdapat 17 buah, terletak di setiap ruang yang berpotensi menghasilkan limbah padat B3 benda tajam seperti IGD, Poli serta ruang operasi. Wadah untuk botol infus bekas terdapat 4 buah, dan untuk drum wadah limbah padat B3 yang terletak di TPS terdapat 4 buah yang berfungsi untuk menampung jenis limbah yang sesuai dengan karakteristik limbah.

Pewadahan limbah B3 yang dilakukan oleh Rumah Sakit Muhammadiyah Babat telah sesuai dengan ketentuan yang berlaku. Pada Gambar 1 merupakan contoh jenis wadah yang digunakan dalam pewadahan limbah padat B3 di Rumah Sakit Muhammadiyah Babat.

\section{b. Pelabelan}

Pelabelan limbah B3 adalah proses penandaan atau pemberian label yang dilekatkan atau dibubuhkan pada kemasan langsung limbah B3. Pelabelan berfungsi untuk membedakan tempat limbah padat B3 dan tempat sampah untuk limbah Non-B3, sehingga pengunjung tidak salah membuang sampah dan untuk mempermudah pemilahan. Label limbah B3 merupaan keterangan mengenai limbah B3 yang berbentuk tulisan yang berisi informasi mengenai penghasil limbah B3, alamat penghasil limbah B3, waktu pengemasan, jumlah, dan karakteristik limbah B3 (PP No. 101, 2014).

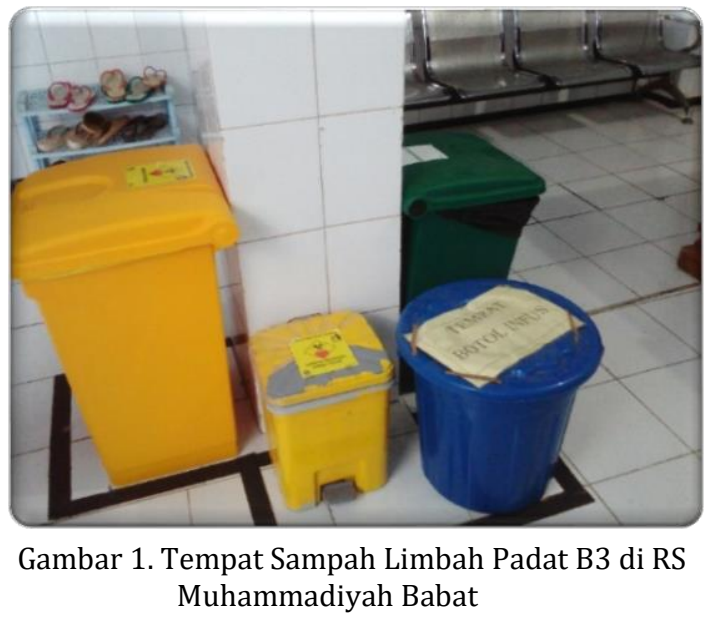

Label yang digunakan pada kegiatan pelabelan di Rumah Sakit Muhammadiyah Babat ini juga telah sesuai dengan lambang atau label yang tertera pada Permen LH No.14 Tahun 2013 Tentang Simbol dan Label Limbah Bahan Berbahaya dan Beracun (B3). Salah satu contoh pelabelan dapat dilihat pada Gambar 2.

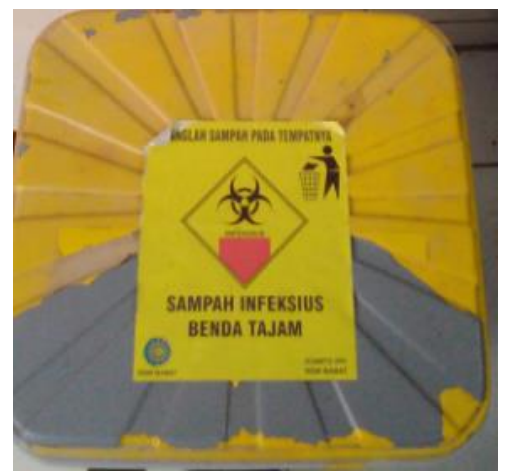

Gambar 2. Pelabelan limbah padat infeksius benda tajam

\section{c. Pengumpulan di TPS B3}

Pengumpulan limbah padat B3 merupakan salah satu pengelolaan limbah padat B3 dengan cara menempatkan 
limbah padat B3 pada tempat tertentu (TPS B3). Pengumpulan dilakukan dengan klegiatan pengangkutan. Menurut Keputusan Menteri Kesehatan Republik Indonesia Nomor 1204 Tahun 2004 tentang Persyaratan Kesehatan Lingkungan Rumah Sakit pengangkutan limbah medis padat dari setiap ruangan penghasil limbah menggunakan troli khusus yang tertutup. Pengangkutan internal merupakan pengangkutan yang berawal dari titik penampungan awal atau sumber dihasilkanya limbah padat B3 ke tempat penyimpanan atau TPS B3. Pengangkutan internal di Rumah Sakit Muhammadiyah Babat dilakukan dengan menggunakan troli tertutup dengan roda kcil, sehingga mempermudah pergetakanya. Troli dibersihkan secara berkala oleh petugas Cleaning Service (CS). Setiap kali akan mengambil atau mengangkut limbah padat B3, petugas CS menggunakan alat pelindung diri (APD) seperti sarung tangan, sepatu boat, dan masker.

Pengangkutan limbah B3 ke TPS Rumah Sakit Muhammadiyah Babat dilakukan dengan memindahkan limbah B3 dari tempat sampah infeksius yang telah tersebuiar diseluruh penjuru rumah sakit serta dari ruang spoel hock (ruang ini hanya tersedia di tempat-tempat tertentu, yang menghasilkan limbah padat B3 gterbanyak) ke dalam Tempat Penyimpanan Sementara B3 (TPS B3) dengan menggunakan troli tertutup, limbah lalu dimasukan dalam drum penyimpanan B3 yang telah tersedia dalam TPS B3.

Pengangkutan limbah padat B3 ke TPS dilakukan oleh petugas CS Rumah Sakit Muhammadiyah Babat dengan rute yang efisien dilakukan pada pukul 05.00 WIB, pengambilan limbah B3 dilakukan minimal 1 kali dalam sehari, apabila limbah padat B3 yang dihasilkan melebihi kapasitas, maka pengambilan limbah padat B3 dilakukan 2 kali sehari. Pengangkutan internal yang telah dilakukan di Rumah Sakit Muhammadiyah Babat telah sesuai dengan peraturan yang berlaku. Pada Gambar 3 merupakan gambar troli tertutup yang digunakan dalam pengangkutan internal limbah padat B3 di Rumah Sakit Muhammadiyah Babat.

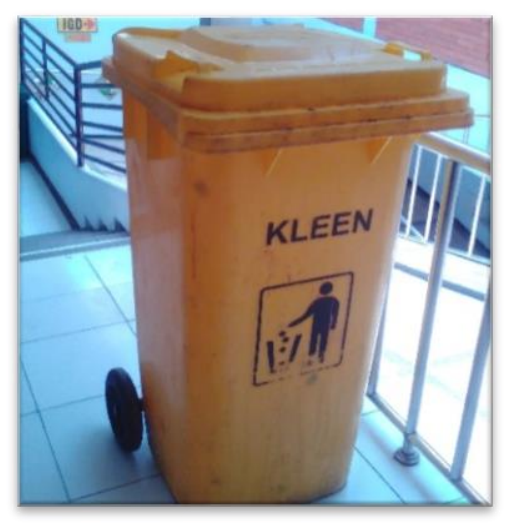

Gambar 3. Troli Tertutup untuk pengumpulan limbah padat B3

\section{d. Penyimpanan Sementara}

Penyimpanan sementara yang dilakukan di Rumah Sakit Muhammadiyah Babat berupa Ruang Spoel Hock serta TPS B3. Ruang Spoel Hock merupakan ruang penyimpanan sementara yang berada di beberapa ruang tertentu yang berpotensi banyak menghasilkan limbah padat B3. TPS B3 merupakan tempat penyimpanan akhir sementara sebelum dikirim ke pengolah limbah. TPS B3 berdimensi $4 \mathrm{~m}^{3}$. Didalam TPS B3 terdapat perlengkapan TPS B3 yang disyaratkan, seperti MSDS (Material Safety Data Sheet), SOP (Standart Operational Procedure), Hand Scrub. TPS B3 ini juga telah dirancang sesuai dengan ketentuan seperti, terhindar dari genangan, tehan dari hujan, dan tertutup. Namun TPS B3 di Rumah Sakit Muhammadiyah Babat belum dilengkapi pendeteksi asap, alat pemadam kebakaran yang mudah dijangkau, peralatan P3K, bak penampung tumpahan, serta peletakanya yang masih berada di area parkir rumah sakit.

Meski begitu TPS B3 di Rumah Sakit Babat telah mendapatkan izin dari Dinas Lingkungan Hidup Kabupaten Lamongan. Jenis limbah padat B3 yang telah mendapatkanizin penyimpanan berupa: semua jenis limbah infeksius, limbah elektronik, produk farmatik kadaluarsa, bahan kimia kadaluarsa, dan peralatan laboratorium terkontaminasi.

Rumah Sakit Muhammadiyah Babat tidak melakukan pencampuran limbah padat B3. Limbah padat B3 yang sejenis dikemas dalam satu wadah atau drum yang telah diberi label, begitu pula dengan limbah padat B3 lainya. Dengan demikian dapat disimpulkan bahwa penyimpanan 
sementara limbah padat B3 di Rumah Sakit Muhammadiyah Babat telah memenuhi peraturan yang berlaku (PP No. 101 Tahun 2014), meskipun masih ada beberapa fasilitas yang belum tersedia.

Gambar 4 merupakan gambar TPS B3 di Rumah Sakit Muhammadiyah Babat yang digunakan sebagai penyimpanan sementara sebelum diangkut oleh pihak ke 3 untuk dilakukan pengolahan limbah padat B3.

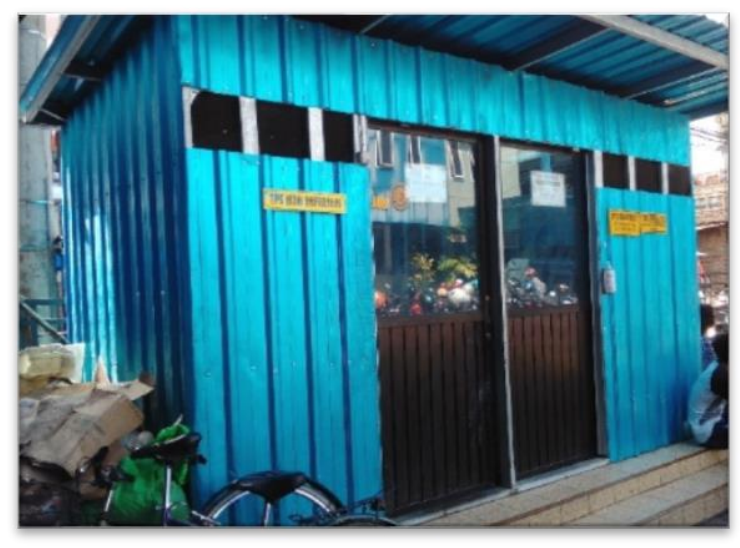

Gambar 4. Tempat Penyimpanan Sementara Limbah Padat B3 di RS Muhammadiyah Babat

\section{Pengangkutan Limbah Padat B3}

Pengangkutan limbah padat B3 dilakukan berupa pengangkutan eksternal atau off site yang dilakukan untuk memindahkan limbah padat B3 dari TPS B3 ke lokasi pengolahan limbah padat B3. Pengangkutan dilakukan kendaraan berupa truk tertutup sesuai dengan kriteria kendaraan angkut limbah padat B3 kategori 1. Pengangkutan eksternal dilakukan tiap satu minggu sekali dan dilakukan pada pagi hari agar tidak menggangu aktifitas masyarakat disekitarnya.

Pengangkutan dan pengolahan limbah B3, Rumah Sakit Muhammadiyah Babat bekerja sama dengan PT. Putra Restu Ibu Abadi (PT PRIA) yang beralamatkan di Desa Lakardowo Kecamatan Mojokerto. Pengangkutan eksternal dilakukan dengan menggunakan kendaraan berupa truk kecil, dengan bak yang tertutup untuk mengangkut limbah dari rumah sakit menuju tempat pengolahan. Pada Gambar 5 merupakan gambar kendaraan pengangkut limbah dari PT PRIA yang digunakan untuk mengangkut limbah menuju tempat pengolahan.

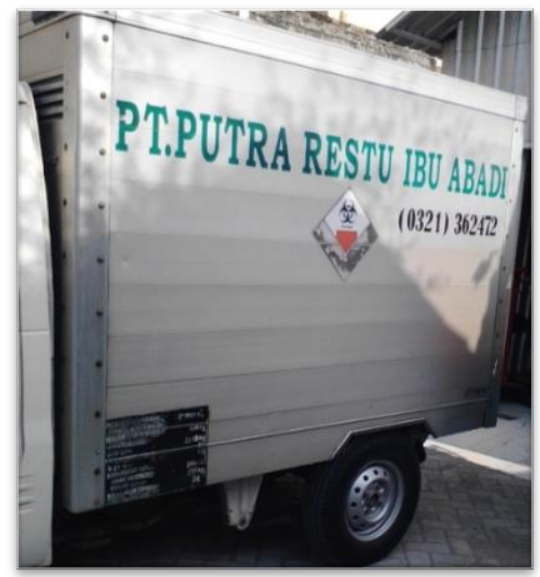

Gambar 5. Truk Pengangkut Limbah Padat B3 P.T.PRIA

\section{Pengolahan Limbah Padat B3}

Pengolahan merupakan proses untuk mengurangi dan/atau menghilangkan sifat bahaya dan/atau sifat racun. Pengolahan limbah padat B3 di Rumah Sakit Muhammadiyah Babat dilakukan oleh pihak ketiga yaitu PT. PRIA, hal tersebut dilakukan karena sarana pengolahan limbah padat B3 seperti insenerator atau teknologi pengolahan lainya tidak tersedia di RS Muhammadiyah Babat.

\section{Rekomendasi}

Pengelolaan limbah padat B3 di Rumah Sakit Muhammadiyah Babat sudah memenuhi persyaratan, meski ada beberapa fasilitas yang belum tersedia. Untuk memaksimalkan pengelolaan limbah padat B3 dan untuk meminimalisir kecelakaan kerja ada beberapa fasilitas dan kegiatan yang harus dilakukan seperti yang tercantum pada Tabel 3 berikut ini.

Tabel 2. Rekomendasi Sarana Pengelolaan Limbah Padat B3 RS Muhammadiyah Babat

\begin{tabular}{|c|c|c|}
\hline No & Keterangan & Rekomendasi \\
\hline 1 & $\begin{array}{l}\text { Pengurangan } \\
\text { limbah padat } \\
\text { B3 }\end{array}$ & $\begin{array}{l}\text { Pengurangan limbah padat B3 } \\
\text { dapat dilakukan dengan } \\
\text { modifikasi bahan, perubahan } \\
\text { teknologi, perubahan teknik, } \\
\text { pengoperasian yang baik dan } \\
\text { lainya }\end{array}$ \\
\hline 2 & $\begin{array}{l}\text { Fasilitas TPS } \\
\text { B3 }\end{array}$ & $\begin{array}{l}\text { - Perlu pengadaan peralatan } \\
\text { APAR yang letaknya mudah } \\
\text { dijangkau. APAR yang } \\
\text { digunakan berupa hydran yang } \\
\text { mudah diguakan dan letaknya } \\
\text { yang dekat dengan TPS B3 } \\
\text { - Kotak P3K digunakan sebagai } \\
\text { pertolongan pertama saat } \\
\text { terjadi kecelakaan akibat B3 } \\
\text { yang ada di TPS } \\
\text { - Saluran dan bak buangan } \\
\text { digunakan untuk menyalurkan }\end{array}$ \\
\hline
\end{tabular}




\begin{tabular}{lll}
\hline No & Keterangan & \multicolumn{2}{c}{ Rekomendasi } \\
\hline & $\begin{array}{l}\text { dan menampung air lindi } \\
\text { apabila terjadi pelindian. }\end{array}$ \\
\hline
\end{tabular}

(Sumber: Data Primer, 2017)

\section{KESIMPULAN}

Kesimpulan yang dapat diambil dari penelitian ini antara lain:

1. Sumber limbah padat B3 Rumah Sakit Muhammadiyah Babat berasal dari ruang bersalin, kamar operasi, IGD, laboratorium, kamar obat, poli-poli serta kantor.

2. Jenis limbah yang dihasilkan berupa limbah padat B3 infeksius dan non infeksius, serta limbah elektronik.

3. Pengelolaan limbah padat B3 di Rumah Sakit Muhammadiyah Babat berupa penyimpanan, pengumpulan (pewadahan, pelabelan, pengangkutan on-site, dan penyimpanan sememtara), dan pengangkutan. Sedangkan untuk pengolahan limbah dilakukan oleh pihak ketiga.

\section{DAFTAR PUSTAKA}

Ananth, A.P., Prashanthini, V., dan Visvanathan, C. 2010. "Healthcare Waste Management in Asia". Waste Management 30, Ha. 154-161

Badan Pusat Statistik Kabupaten Lamongan. 2018. Banyaknya Penduduk dan Keluarga di Kecamatan Babat 2014. Lamongan, Indonesia

Departemen Kesehatan Republik Indonesia. 2004. Sistem Kesehatan Nasional. Jakarta, Indonesia

Kalpana, V., et all. 2016. Biomedical Waste and Its Management. Journal of Chemical and Pharmaceutical Research ISSN 0975-7384. India

Komilis, D., Fouki, A., dan Papadopoulos, D. 2012. "Hazardous Medical Waste Generation Rates of Different Categories of Health-care Facilities". Waste Management 32, Hal. 1434-1441

Menteri Kesehatan Republik Indonesia. 2004. Keputusan No. 128 tahun 2004 tentang Kebijakan Dasar Pusat Kesehatan Masyarakat. Jakarta, Indonesia

Pokja. 2012. Strategi Sanitasi Kota Lamongan. Kelompok Kerja Sanitasi Kabupaten Lamongan. Lamongan, Indonesia

Presiden Republik Indonesia. 2014. Peraturan Pemerintah Republik Indonesia Nomor 101 Tahun 2014 tentang Pengelolaan Limbah
Bahan Berbahaya dan Beracun. Jakarta, Indonesia 